\title{
Teaching Architecture as an Intervention in Thinking: The Moratuwa Experiment Revisited
}

\author{
Ranjith Dayaratne
}

\begin{abstract}
Apart from Architecture itself, architecture students learn many other things during their course of studies, both factual and otherwise. This is indeed unique since most other disciplines may not be able to claim the same about their courses of study. Obviously, as a student, one may acquire knowledge unrelated to the subjects they study in the process of maturity and growing up in every discipline, but most academics would not necessarily consider it a great achievement that their students have learned nothing in their discipline but other things during the course of study. In one year of studies in architecture at the University of Moratuwa in Sri Lanka in fact, quite the contrary was happening and the students took great pride that they are not leaning architecture per se, at least in one year of their 6 year course. A recent research uncovered that the students believe they learned a great deal of 'thinking' but very little in architecture. This paper examines a student evaluation of the teaching / learning practice that prevailed in the $5^{\text {th }}$ year studio in 1998 at the Department of Architecture at the University of Moratuwa, which is a part of a programme known as the Moratuwa Experiment and discusses its impact upon the students' thinking.
\end{abstract}

\section{Introduction}

The pragtice of architecture is generally considered as employing scientific knowledge and artistic skills to make environments for habitation either with or without buildings. Thus architectural education comprises gaining scientific knowledge as well as acquiring artistic skills. In all courses of studies around the world, there are subjects related to building materials and construction, climate and environmental factors, engineering structures, social sciences and more importantly, design. Design is considered to be the main teaching program and is indeed so treated that the entire teaching practice of architecture is focused upon the studio; once considered the ideal place for teaching design. More recently however, criticisms have come particularly from the academic community that the studio is inherited with its own weaknesses (Lee,1998. Soon, 1998). At the same time, some also argue that one of the main problems of teaching is also that the concepts adopted for discussing architectural design in the studio are far removed from the real world. Hence there is also a call for theoretical shitts in the interpretation of architecture more reflective of the Lived-in-World (Schultz, 1971,1980) that will help not only teaching architecture but also the practice (Bologner, 1985). The dichotomy of theory versus practice and the studio versus outside world continues to divide the academics and practitioners alike. Nevertheless, Studio is still considered the best available methodology for design teaching. Theory indeed is expected to be derived from practice so that the practice can be theory-driven (Dayaratne, 1992).
But how does teaching of design happen in the studio? What are the main activities going on in there and how does it differ from one course to another or one year to another year? What are its weaknesses and how could they be overcome? These indeed are legitimate questions to ask.

\section{Studio as an Experimental Laboratory}

Design studios are ideal experimental laboratories if only the teachers and students would like them to be treated so. In most schools of architecture, they are experimental laboratories for the exploration of concepts of art, concepts of space, systems or methods of construction, and indeed approach to design.

Only rarely however, they will also be experimental situations of methods of teaching. The questions about what projects to be introduced, and what programmes to be followed are often asked, but it is generally felt that how to teach design are known and thus what is necessary is to get on with teaching and get on with getting the students to work harder and harder and thus do better. At the University of Moratuwa, particularly in the design studio of the fifth year, these have indeed been the central questions being asked almost every year. The questions are asked not only by the teachers themselves but from the students and a practice has emerged which appear to differ distinctly from most teaching practices, and results believed equally distinctly different. The author of this experiment has written extensively and has claimed the development of a new way of teaching that it entices and engulfs the 
students in thinking about architecture. If this is the case, surely, we should ascertain how this happens and to what extent the students subject to this experiment indeed have become and are becoming designers with exceptional skill and talent which is what all schools of architecture aspire to produce.

This research was an attempt to examine the potentials of the practice of teaching of architecture perceived primarily as an act of intervention in thinking which the Moratuwa experiment claims to augment.

\section{The Moratuwa Experiment}

What is being referred to as the "Moratuwa Experiment" is a way of design teaching that has been implemented at the Department of Architecture at the University of Moratuwa from about 1981 conceived and articulated by a single teacher and perhaps some of his followers. Sri Nammuni, the educator who invented, articulated and implemented this experiment has written (1991a,b,c,d and 1992) relating the origins of the experiment to his initial years of learning as a student with a degree of dissatisfaction about the way he was educated and subsequent discovery and acquisition of specific attitudes, skills and practices of both teaching and learning. It is claimed that the experiment has innovated new thinking on design teaching, design assessment, interim crits, design tutoring, and design administration.

One of the major premises behind the Moratuwa Experiment is that most of us teaching architecture have failed to teach architecture and instead adopt a practice of cloning the students. Sri Nammuni argues that "In the cloning approach, we continue to treat students as apprentices teaching by example, through giving of alternatives: "if I were you' solutions" (1991a:22). He claims that "we in architectural design teaching have failed to teach- to listen to the students; to understand their solutions; to analyse them, with them, to their roots and mode of thinking; to discuss, correct and re-orientatate it so that alternative and more mutually acceptable solutions may be formulated by the students themselves." (1991a: 22) According to this interpretation, the students who are subject to the 'cloning process' eventually become like their teachers, doing things in line with the thinking of the teacher, rather than of their own and the designs that are generated in the studios are thus more of the teachers' rather than of the students' themselves. Sri Nammuni argues that this practice makes 'clones' of the teachers, who can only imitate their teachers thinking and therefore lose the development of their own thinking.
The single-most important principle of the Moratuwa Experiment has been that creativity arises from within, from the internalization of the thinking process and not through the recourse to external agencies whether they are the computers or patterns (Sri Nammuni,1991d:18). It is based on the idea that architectural design deals with problems of multifaceted nature, the resolution of most do not necessarily result in architectural form and space; architecture having been defined primarily as an art. Thus, it focuses upon the location of problems that are architectural in nature; architectural problems to be recognized as the major problems the resolution of which should give rise to form and.space. Nevertheless, it also argues that the resolution of even the architectural problems creatively is humanly impossible and requires looking beyond the human condition. Adopting an essentially Eastern interpretation, Sri Nammuni argues that it requires what he calls 'divine inspiration' to which one then becomes the vehicle for seeking a satisfactory solution. The means with which we gain access to this faculty is the meditative technique of divergence followed by rapid convergence, which results in insight. Sri Nammuni writes that "a design process must therefore take us beyond our ego, and help us transcend boundaries of the human condition -into divinity that exists within us and without us" (1991d:18). This may also be interpreted as having access to the collective unconsciousness (Jung, 1938).

Thus the Moratuwa Experiment claims to have devised ways of listening to students, discovering their solutions, orientating them to discover themselves and their own ways of design thinking and gaining insights that form the guiding force for creative design conceptions. Moratuwa Experiment was considered to have reached a level of refinement in its implementation around 1995 having resolved most of the major issues and criticisms (see, Sri Nammuni, 1991a,1991b,1991c, and 1991d) levelled against it by both students, followers and other teachers when Sri Nammuni reported that "its application is now seen in many guises through the early experimenters (children of the Moratuwa Experiment) who have in turn become teachers with their own variations".

\section{The Research}

\section{An Examination of Students' Learning within the} Moratuwa Experiment:

In October 1998, when the $5^{\text {th }}$ year course of study was almost completed, and the "post mortem" concluded, it was revealed that the students were 
extremely happy with the year of study and claimed that they enjoyed being there for an year. They worked hard, learned a great deal of things but also admitted that they did not learn much in "Architecture". The researcher taught social and behavioural studies to these students but was not involved in teaching design in any way in this year. Since the discovery of the students' evaluations of this course was interesting and raised many questions about the phenomena of teaching architecture as an intervention in thinking, it was decided to probe into this further. This group of students were considered a good sample to examine the questions and it was then decided to carry out the following research on what they learned, and how. Students volunteered to be involved and it was felt that the Moratuwa Experiment was worth being examined externally in order that lessons could be learnt and the practices that emerged through the experiment could be valued and thereby its positive aspects strengthened, refined and cultivated.

\section{The Research Questions}

Three specific research questions were posed at this inquiry.

1. What do the students perceive as the outcome of teaching in the design studio of the fifth year in architecture at the University within the practice of the Moratuwa Experiment?

2. What methodologies are adopted there and how do they produce such an outcome?

3. What are the salient features of this practice and what conceptual biases does it propagate?

\section{The Methodology.}

The three research questions are explored employing different methodologies. In terms of the issue of how the outcome is perceived, it was thought that the students' own evaluations were of significance rather than anything else. The methodology adopted to ascertain this in this research was to elicit mental constructs of the students by means of an informal unstructured interview. The Personal Construct Theory (Kelly, 1955) proposes that people hold mental constructs of experiences, of persons, of objects, and of situations which can be systematically unraveled to ascertain their patterns of existence particularly their nature and the tensions that exist in them. In therapeutic examinations of mental patients, Personal Construct Theory is employed as a means of ascertaining the causes behind psychologically disturbed patients. In psychological research, the Repertory Grid Technique (Kelly,1955; Honikman, 1976), and the Sorting Task (Canter,1977) are popular techniques that are employed in unraveling people's perceptions and conceptions of their surroundings.

A mental construct is a clustered set of ideas that are contained and nurtured as a composite set by a person in a continuous process of experiences and encounters. We hold such constructs pertaining to almost all objects, persons, situations, events and in fact concepts that we have come in contact. These constructs are believed to fashion the way we think and act. In fact, the process of education can be said to comprise of specific and conscious programmes to organise, cultivate and fashion these constructs in particular ways and in particular directions.

In eliciting constructs, the respondents are allowed to come out with any concept that comes to their minds. No distinctions are made between relevant or irrelevant ones, significant or trivial ones or good ones or bad ones etc. In other words, respondents are totally free to say what they like. In recording however, the constructs will be more clearly articulated with consent and agreement with the respondents. Once the constructs are elicited from a group of people, it is possible to examine the nature of their coherence and commonality as a way of recognizing the significance of their presence. In so doing, the underlying reasons for such commonality and coherence or otherwise can also be ascertained.

\section{Task One}

This research examination was rather spontaneous so the students could not expect to "have their answers ready" or could have been groomed to answer in a particular way. At the end of one of the lecture times, towards the end of the year, while the students were just wrapping up, a casual discussion was initiated about the year of study, its outcome and their feelings about the course. Each student was then asked to say what he or she thought they did study in that year. These students' "constructs" of their acquired learning were then listed, until the entire class could elicit such construct no more. Once these constructs were listed, all the students were asked to identify if they thought that they also belonged to any one of these constructs or more and the numbers picked up. 
22 categories of constructs were elicited as follows.

\begin{tabular}{|l|l|l|}
\hline Category of Construct & Frequency & Type \\
\hline Discipline of thinking & 21 & Thinking \\
\hline Order of thinking & 21 & Thinking \\
\hline Communication with others & 11 & Communication \\
\hline Different ways of thinking & 25 & Thinking \\
\hline Ways of building up an argument & 15 & Thinking \\
\hline To be critical of others views & 05 & Persona trait \\
\hline Depth of thinking & 21 & Thinking \\
\hline New ways of thinking & 15 & Thinking \\
\hline Different Interpretations & 14 & Thinking \\
\hline Adapt yourself to several situations & 18 & Persona trait \\
\hline To build up a philosophy & 17 & Thinking \\
\hline Ability for self evaluation & 07 & Thinking \\
\hline Organization of your work & 09 & Persona trait \\
\hline Discipline of Life & 03 & Personal trait \\
\hline Working under stress conditions & 29 & Personal trait \\
\hline How to become a rebel & 02 & Personal trait \\
\hline To look at things from different standpoints & 05 & Thinking \\
\hline To respect others views & 18 & Personal trait \\
\hline To exploit ourselves & 01 & Personal trait \\
\hline To have an opposite argument & 04 & Thinking \\
\hline About the attitudes of the tutors & 01 & Others \\
\hline To recognize your orientation within views & 05 & Intellectuality \\
\hline
\end{tabular}

8 out of 22 Personal Traits

11 out of 22 Thinking

1 out of 22 techniques of intellectualization

1 out of 22 Individual

1 out of 22 About others
$36.5 \%$

$50.0 \%$

$4.5 \%$

$4.5 \%$

$4.5 \%$

What is most interesting in these findings is that $50 \%$ of the constructs were to do with ways of thinking And $36.5 \%$ of constructs contributed to personal traits. Other facets of individual development Included such skills as, working under stress conditions (29) adapt yourself to several situations (18) to respect others views (18) organization of your work (09) to be critical of others views (05) to have an opposite argument (04) discipline of life (03) how to become a rebel (02) and to exploit ourselves (01).

In the category of thinking, the students thought that they learnt, Discipline of thinking, Order of thinking, Different ways of thinking, Depth of thinking, New. ways of thinking, Ways to interpret differently, Building up a personal philosophy, to self-evaluate, to have an opposite argument, and to look at things from different stand points.

And most interestingly, $60 \%$ of the students felt they learned different ways of thinking. Thus what is clear from these findings is that the $5^{\text {th }}$ year teaching in fact intervenes into the students' thinking. process quite consciously. Its major articulation seems to be to inculcate in the student a way of thinking that will enrich him as a person, enable him to develop his own approaches to the world and indeed architecture. The major premise here is that "thinking" can be learned, has to be learned and that architecture students have to do so quite consciously.

How is this conscious intervention in thinking articulated in the studio? What are the roles and relationships between the students and teachers, and what lessons are there to be learnt from such experimentation? These questions were probed further into with discussions with the students and a number of salient aspects of this practice were unraveled. 


\section{Task Two}

The task two involved a further, more focused and probing informal interview with the same group of students. The discussions were held in a small group among the volunteers who felt they were able to consciously understand the different stances taken, and were therefore able to articulate the salient features of the practice. This was also corroborated with the writings explaining the methodology and the salient aspects of the practice were recognized.

\section{The Findings:}

There are number of aspects that are notable in the Moratuwa Experiment. Firstly, it adopts a clearly articulated theoretical interpretation of architecture. Secondly, it strategically deals with the students focusing on the ideas they possess and making a deliberate attempt to challenge them. Thirdly, it follows a way of dealing with the students in the studio and outside that engages them constantly with the teachers and peers in a mutually enlightening educational process. The conventional teacher student relations have been abandoned and the new and strikingly different theoretical, conceptual and social context places the student in a new position of the world that has not been seen before forcing them to view develop and construct alternative understandings of things that have been taken for granted. This approach can in fact be termed as "challenging the taken-for-granted" which exists in the field of architecture in abundance. Almost every assumption in the architectural design studios is generally taken-for-granted not only at the Department of Architecture at the University of Moratuwa but everywhere else.

The study noted that the Moratuwa Experiment employs a theoretical interpretation of architecture as art, fused with an interpretation of manenvironment interactions. Thus its philosophical base, although related to art is not aesthetically inclined. It burrows the ideology of art as a mechanism to articulate the symbolic, emblematic, affective and arousing characteristics of the material components of architecture but ignores the processes of making and crafting. In the case of the man-environment interpretations, it takes a predominantly deterministic stand immersed in positivism. In other words, it takes the position that architecture has a predominant social role to play and that good architecture can make good people and good societies. To put it in the words so popular in the Moratuwa Experiment itself, the right environment will result in "the right frame of mind" which will induce the "right mode of Behaviour".

In the process of challenging the taken-for-granted, the Moratuwa Experiment also takes a strategic approach to dealing with the students. In contrast to the common practice of teacher being positioned above the students, the Moratuwa Experiment places the students in par with the teacher allowing them to question, challenge and therefore think and express freely the ideas and concerns they have. This particular shift is found to be an exciting opportunity the students enjoy and therefore utilize to develop their own ways of thinking. On the one hand there is the absence of an authoritative view and person above, and on the other, there is a strong and clear view that the student can confront without the fear of being pushed down. Indeed, the students are encouraged to 'look for' alternative views simply to engage in the debate that leads them to discover their own ways of thinking. The most notable characteristics of this practice can be summarized as follows.

\section{Architectural Theory}

- Focusing on and demanding explicit theory before practice;

Focusing on architecture-people interface;

Advocating an architecturally deterministic perspective;

Focusing on objects and things and particularly their expressions;

- Focusing on an idea popularly known as "Environmental Quality" as the basis of design.

- Insistence of explicit design methodology;

- Insistence of a singular, rational and logical method;

\section{Teaching Practice}

- Raising fundamental questions about the student and his surrounding;

Questioning accepted norms and beliefs;

- Asking the student the definitions of ideas and concepts that they deal with before these ideas are employed in design;

- Challenging student's ideas with alternative views;

- Asking other students to challenge the ideas of each other;

- Discussion of casual observations, trivial events as much as serious debates;

- Doing away with the teacher student barrier as much as possible and the notions that the student is less than the teacher;

- Smaller group-discussions;

- Continued presence of the teacher in the studio engaged in discussion while the student joins and takes time off as and when he feels;

- Allowing the students to challenge the teacher.

- Carrying the academic discussion from one day to another on the same issue both in the studio and outside;

- Engaging the students and teachers at intense discourse whether relevant to architecture or otherwise but drawing parallels to the practice of architecture wherever possible; 
The major focus of the Moratuwa Experiment can however be located in its attempts to evolve a design process that burrows from the interpretations of art (Coomaraswamy, 1981) and environment-behavior relations and design methods (Jones, 1970). Indeed, it places a great deal of emphasis upon creative thinking, creative process and its linkages to the design activity (Brill, 1960). In order to do this, it employs the interpretation of architecture as art offered by Coomaraswamy (1981) who argues that art is in the making of it and that the artist transcends the human condition and achieves divinity momentarily at the point of conceiving and creating art. The argument here is that as the primary purpose of art is to evoke contemplation, the creation of environments as art forms must also do so. In other words, architecture as art must create environments that provide correct psychological and physiological conditions for specific activities to occur. It is notable at this point that the interpretation of art is extended here to accommodate a relation with the 'user' and his behaviour; a position related to the environmentbehaviour relations. The distinction between the role of art to enable contemplation and psychological conditions that determine human behaviour, is bypassed to build the argument.

Once this is established, the focus shifts to the user whose qualitative and quantitative needs must be met through architecture. Moratuwa Experiment argues that once the users' problems are understood by the architect, they become the architect's problem that should be resolved in the solitude of his mind. The solution comprises two aspects; form and shape, the form being the outcome of the resolution of the problems by the architect and the shape being those modifications and personalisations of the form by the user. Thus the role of the architect is defined as that of form-giving, and the role of the user is identified as that of 'shaping'. Form making involves the adoption of an appropriate language and creating a message that is generated through the process of understanding the user's needs, aspirations and other socio-cultural and physical demands.

The method or the design process adopted constitutes both externalized activity as much as internalized activity. The first of this process is what is called the intellectual phase and involves the examination of the issues and problems posed by the design project. Problems are segregated in terms of their relation to the many facets of architecture. For example, there are quantitative problems such as construction problems, service problems, circulation, access, site, etc. as much as qualitative problems such as symbolism, expression, privacy, etc. The intellectual phase begins with sensing the problem area and the students are made to converge to architectural problems among which a major architectural problem should be located. The architectural problems are almost always considered to be socio-spatial problems rather than technical problems of construction, composition or planning. The nature of the social problem is studied, both at the micro and macro levels. An attitude of causality of human behaviour is adopted where it is argued that specific environments can generate specific human actions.

The resolution of the major problem is transformed into the primary objective of the project re-phrased in terms of a creation of a specific frame of mind that can be generated through a 'desired environmental quality' that the design should create. This is defined as the concept that leads to the conception of imagery constituting the form of the building, its character, composition and geometry etc. Clarity of expression is sought, complexity is added and multi-valence is achieved in the subtle transformation of the imagery in response to the climate, the site, the secondary requirements etc.

The Moratuwa Experiment follows a logical thinking process in identifying the major problems and then moves on to lateral thinking in seeking the transformation of the major problem to the concept and the formation of imagery. It argues that the lateral thinking taps the collective unconsciousness and internalizes the process and enables releasing the architect from the natural sense of ego-centricity that usually prevails in the designer. It claims that the process encapsulates the principles of the 'Timeless way of building' (Alexander, 1979) and transforms it to a teachable, learnable design process. In Sri Nammuni's words, 'it has succeeded in linking the timeless way to the universal meditative techniques of divergence and convergence which climaxes in insight; perhaps divine insight" (Sri Nammuni, 1992: 47)

\section{A Critique of the Moratuwa Experiment}

Interestingly, Moratuwa experiment has received different responses from students and from teachers. On the one hand, most students are excited and attracted to the innovative, logical thinking that generates a deductive argument focused on a recognizable facet of the design problems and enables the students to unravel the complexity of many design projects. It helps the students to locate a significant, convincing argument for generating and then defending a design proposal, which is otherwise extremely daunting. The process recognizes the architect as a social-reformist, whose contribution in the world appears to make a distinct difference to the people. The architect is placed on the pedestal and thus is made to bear a sense of authority, power and purpose which the students find rewarding to aspire to. The line of reasoning helps the students to find a concept that can be verbalised, which is 
otherwise a matter of 'groping in the darkness'. In most schools of architecture, students are grappling with all sorts of problems unable to locate a 'concept' and when found, they will not find it easy to defend. Moratuwa Experiment clears the way for them and thus the students are undeniably fascinated by the tangibility of the process, its visible social relevance and the ease at which forms can be generated and defended.

On the other hand, most other teachers are not convinced. They see the design process of the Moratuwa Experiment too logically constructed and its concepts cold and impassionate. They feel that it reduces architecture to the construction of a univalent form lacking in spontaneity and intricacy, contrary to the fact that the Moratuwa Experiment itself claims to focus on the qualitative. Further, they see a lack of opportunity for innovation and creativity which are seen as the pursuit of forms that are 'interesting', 'exciting', and 'playful' on their own right. Moreover, most do not believe that architecture can solve social problems in the way Moratuwa Experiment articulates. Instead, design is seen as a practice that evolves built-forms in the hand of the architectcraftsman in a process that is un-verbalized and unverbalizable. Teaching is seen largely as a practice of apprenticeship, the 'talented' acquiring the techniques from the 'guru', the right and wrong being recognized mainly from the 'nodding', appreciation and rewards offered in terms of repute.

Design assessment of the products of the Moratuwa Experiment thus suffer from this un- reconciled dichotomy once when the students are out in the field, particularly facing the unconvinced, whose eyes are set more in the taken-for granted aesthetics of the beautiful and the sublime. Nevertheless, the practice continues much to the benefit of the students and teachers alike whose everyday design activities are continuously brought to confront the Moratuwa Experiment in various guises. Undeniably, both teachers and students are forced to engage in thinking on the issues willingly, grudgingly or otherwise.

It is indeed necessary to understand this lukewarm response from the academia that contrast with the enthusiastic response of the students. In this respect, it is possible to locate some conceptual orientations of this teaching practice that seem to be at the core of this dichotomy. They seem to disable the students' indulgence in emotional immersion of the design activity and prevent them from being passionate about design. In fact; the Moratuwa Experiment seems to order and regiment the vibrant and lively energy that generally drives students to be creative explorers of forms leading to the recognition as good designers. In other words, it seems that some of the practices of the Moratuwa Experiment inculcates in the minds of the students, concepts and attitudes that are detrimental to wholesome design practice, although they seem to enhance their capacity to "think logically". Deductive thinking seems to be fostered at the expense of arousing the students 'being-as-designer' and 'becoming-a-designer'.

One of the key concepts of this nature is the reference to the 'user;' that begins predominantly with the teachings of the fifth year. Let us examine the plausibility of the term user and its connotations and implications.

\section{Use and Users}

Within the paradigms of the Moratuwa Experiment, there was a notable reference to people as "users" of built-environments. On the face of it, it appears that these references indicate an increasing concern about peopte in whose world the architects act. While this may be seen as a positive development in the architectural inquiries, it also indicates a certain kind of misconception about the people referred to by this term. In other words, it is argued that underlying this reference is a way of seeing the whole spectrum of actors involved in the making and habitation of the built-environment which is insufficient and indeed illconceived.

The term "user" is generally derived to emphasize the fact that peopli: "use" the spaces that architecture provides. In the general sense, this seems quite appropriate and fair that all those who use buildings could conveniently be referred to as users. But what does use mean and what does the term user imply?

Usually, "to use" implies that something exists there for use, and that in a certain process something is consumed, and thus is not available any further. If we apply the commonly held meaning for "use", once something is used, it must reduce from the position it existed prior to such use. For example, if a pen is used, it will have less ink than before. If a paper is used for writing the empty area available for writing will reduce. If shoes are used, then they will wear away. Clothes used are worn out. Used- things indeed attract less value. Their life times reduce when used, but the possibility for use will remain unchanged if unused. In other words, the users seem to take away from the things in the process of use. However, this interpretation of use and users seem applicable only to the use of objects rather than spaces. Objects; utensils, accessories and machines get used up and the users seem to consume an essential aspect from these objects that make them usable.

Use of space however cannot be looked at this way. Buildings and spaces are also used, but do not necessarily lose value, or are reduced from being 
used. A room is not available fo: someone else only when it is "being used". It will then be available again, once the "users" leave. Rooms and spaces can be used over and over for different purposes from time to time and by different "users". Indeed rooms and spaces acquire value with use and become usable only if they are constantly in use. Imagine a room that is not used for some time and therefore is "abandoned". Such a space is likely to gather an aura of "unused-ness" and therefore is unlikely to be usable until it is brought to the level of "usability".

Use of space is thus essentially different from use of things. Use of things devalues them while it is the use of space in fact that adds value and meaning to space. If this is the case, the "users of spaces" must also be essentially different from the users of things. However, it seems that when we employ the term user to refer to those who occupy and utilize a space for doings something, we mean the very same as the users of things. As Wilk (1990) points out, we seem to employ the term user in the way we use the term consumer to mean somzone who uses up something.

It is noteworthy in this regard that treating the builtenvironment as a product for consumption is not unusual in today's world. Nevertheless, the complexity of this relationship cannot also be denied. Wilk (1990) for example points out that although the house is often perceived as a consumer good, it is also seen more as a symbolic entity and a space to live. Built-environment is seen as a reflection of social relationships, symbolizing, mediating or signaling social status, as a cultural and cosmological text and providing contexts for privacy, territoriality and personal space. In this sense, the people who are believed to "use" the built-spaces and builtenvironments and therefore are categorized as users seem to have a more complex relationship to the built-environment than being mere consumers of spatiality. For this reason, it is suggested that the view of people as users or as mere consumers is an ill-conceived one. Indeed, the emphasis on the term user and its varied connotations seem to drive the student to look at the entire process of people-space relationship from a consumerist mechanistic perspective. Significance of people's 'being-in theworld' has been ignored. As Bachlard (1964) succinctly demonstrates, people are not mere users of built-space. They live in them and make them become what they are. People "dwell" in space and it is this act of "dwelling" that is significant in the livedin-world (Bachlard,1964; Heidegger, 1971; Schultz, 1971,1980;Lerup,1977). Dwelling and habitation enables the 'poetics of space' to emerge and engage the dweller to unite with space as part of his "beingin-the-world'. Architecture is the making of a 'poetic spatiality', or 'spatial poetry' that needs most of all an understanding of people as dwellers rather than users.
It is evident very clearly that in the Moratuwa Experiment, the act of "dwelling" and "habitation" have been negated in the process of reference to "users". The reciprocal relationship that exists between them and the resultant 'making of the places' in the unity of people, things and spaces and their connotations have been totally undermined. The students perceive the world as being constituted of an 'objective' material world that is separated from the 'users' who await the consumption of this world. The absence of a holistic view of the world as a collective construction by the people, things and spaces simultaneously, prevents the students to be intuitive, creative, and indeed become passionate about their design activities and thus craft the spaces through design as sincere and true artists they themselves being 'other poetic dwellers in space'. Instead, there is an externalized preponderance of user analysis generating built-form; the two remaining separated to be united.

\section{Environmental Quality and Character}

The other concept that seems to create a mechanistic perception of architectural space and has therefore become counter-productive in the design process is the reference to the "Environmental Quality". In the Moratuwa Experiment, the concept of environmental quality emerges as an all-encompassing basis for all design interventions. Once again, this paper argues that the term deprives the student from recognizing and responding to spatial experience in its fullest sense. A recent survey of post-graduate CDP (Comprehensive Design Project) reports indicated that about $90 \%$ of the post graduate students (sitting for the final examinations one year after the fifth year) depend entirely on an environmental quality that is supposed to exist in more or lesser degrees in spaces to be created in a specific project. Always named, these qualities are identified as being "4riendly", "intimate", etc.

The term environmental quality is an interesting one. Rapoport (1981) has pointed out that environmental quality must be viewed not as a single construction but as a collective one. Thus he proposes what he calls an "environmental quality profile" as a way of recognizing the overall feel of a setting resulting from numerous physical social, cultural political and psychological facets. Environmental Quality as he argues does not exist as a result merely of the builtenvironment. The definitions offered in the Moratuwa experiment however are reductionist that they ignore all other aspects that contribute to spatial experience except those of the built object. Even if we accept the argument that architect is able to manipulate only the built-form, the meanings of which matter in design, there is an obvious lack of an understanding of the way in which meanings are derived. Moratuwa experiment believes that the shapes and forms by themselves possess such environmental quality in 
their particular configurations alone, a view that is neither substantiated by research nor by the examination of actual meanings. Instead, it is the imagination of the designer that is brought to bear upon this interpretation. Moratuwa experiment calls this lateral thinking.

Two questions arise in this reference to the environmental quality. The first of these relate to the concept of environmental quality itself. Alexander (1979) who has researched extensively on the concept of environmental quality rejects naming such qualities for the simple reason that once a name is given, it reduces itself to something less than what exactly it means and really is. Thus Alexander goes onto talking about quality in the shape of "quality without a name" (Alexander, 1977). In fact, quality is an experience and differs from characteristics. Quality depends on the perception of the person, and is a manifestation of an interaction between the characteristics of an object and a person. As Pirsig, (1974) points out, quality does not reside in the object or the environment alone.

It is suggested that the idea of the environmental quality as it is employed in the Moratuwa Experiment is misconstrued and makes the student believe that it exists as an objective reality external to the person. Given this interpretation, most students look for a word to name the quality; the concept that is supposed to generate architecture. Once named, the students are reluctant to give it up and are unwilling to see anything but this quality in all his/her designs. Not only are the qualities named, they are believed to determine the way in which people live and do things in those spaces. This is a theoretical position that negates the variety that exists in every day society and mechanizes the human relationships to space so much so that people are seen as helpless entities subject to the torture of architecture.

\section{Architectural Deteminism as the Basis}

Interestingly, "a theory of architecture" that is entirely hinged upon the "desired environmental quality" has come to underline this thinking. This theory stems from a perception that architecture determines human behaviour and that the central cause of peoples' behaviour is indeed the environment. Its simplistic notion and the seemingly distinguished position it ascribes to the architect as the "Form Giver" of the environment has caught popular imagination and the students have accepted these ideas in the absence of any alternative thought. According to this view, making architecture is about creating a desired expression from the appearance of the building, and about creating a "desired and ideal environmental quality" that will determine given human actions. A list of environmental qualities have emerged now vehemently advocated as the panacea for making architecture socially relevant.
This indeed is an extension to ideas that emerged as early as 1970 s popularly known as Environmental Determinism or Architectural Determinism. Architectural determinism is informed by the belief that there is a causal relationship between a physical environment and the behavior of it occupants. As Broady (1968) argued, it is a kind of architectural positivism: the view that prescriptions for architectural design might be derived from laws about the reaction of human beings to their environment, analogous to the laws of natural science such as physics. In other words, it assumes that people are passive objects whose actions are moulded by the interplay of forces in their environments. Canter (1977) demonstrates very clearly that the perception of architecture determining human behaviour is a misconstrued simplistic notion that is founded on imagination rather than facts'

\section{Concluding Remarks}

This research was initiated on the assumption that the Moratuwa Experiment is a unique teaching practice that needs to be recognized for its merits and lessons should be learnt from experiments such as these to advance design teaching, evaluation and architectural practice. It was prompted by the belief that there was something significant worthy of discussion there although skepticism and cynicism against these ideas abound. This study was able to record and discuss the salient aspects of this practice and offer for discussion the probable weaknesses or misconceptions as found by the writer. The experiment has raised fundamental questions about teaching design and opened our eyes to the many facets of opportunities available to teaching.

The interesting dichotomy that prevails over its acceptance indeed warrants further studies. On the one hand, most students seem quite taken up and value the exposure and opportunity they encounter in this teaching practice that is believed to enrich them intellectually. If that is the case, university education can ask for nothing more from teaching, and this kind of teaching must be encouraged, recognized and valued. On the other hand, most teachers seem skeptical and do not believe that this teaching facilitates the students to learn 'architecture'. Ironically enough, the subject matter at the core of teaching is architecture and the perception that learning is unrelated to architecture stems from the perception that social issues are less architectural than the spatial issues. Perhaps a fine to balance is needed between the two and the focus must shift towards the examination of spatiality, spatial craftsmanship and indeed spatial experience. In this paper, some discussion was offered that may explain the reason for the skepticism. As Nammuni generally points out, the Eastern approach to such issues has generally been 'quiet murmur' rather than open and sincere debate. Nevertheless, this 
dichotomy cannot go unnoticed in an academic environment, and this study was meant to do the breaking of ice in this attitude.

The study demonstrates that the students feel and believe that they learn a great deal, particularly in looking at their own architectural upbringing from an entirely different perspective. It is indeed justifiable for Moratuwa Experiment to claim that it teaches architecture as an intervention in design thinking. This is found to be the most exciting outcome of the fitth year exposure that was present in the year 1998 and before. The students whose ideas of architecture having been allowed to grow up unconsciously and therefore inarticulated, receive a challenge and confrontation in the fifth year and thus become live and explicit. It raises questions never asked before and exposes ways of looking and therefore thinking about the same aspects in numerous different ways. This exposure and experience, the students admire very much and consider a tremendous input to their development. Thus they claim that they learnt a great deal, are satisfied with the exposure and feel content of having been intellectually aroused. University education no doubt is expected to do so and do it consciously and effectively particularly at the postgraduate levels. In this sense, this experiment marks as a significant achievement and contribution to architectural thinking and the exploration of the design studio as an experimental laboratory of design teaching practice.

This study demonstrates that the issue of teaching is not as simplistic as getting on with teaching and doing it harder and harder as most seem to believe. Experimenting is needed although it is better if they are driven by clear and profound theory that is holistic and natural. It is believed that this paper will incite the academia to debate the issue and that this teaching practice will emerge more refined and healthy for the benefit of both the teacher and the students.

see canter, D V (1977) for a good discussion of the fallacy of Environmental Determinism.

\section{References:}

Bachlard, G (1964) The Poetics of Space, Boston: Beacon Press.

Bologner, Botong (19) A Phenomenological Approach to Architecture and its Teaching in the Architecture Studio, in Seamon, D \& Mugerauer, R. (eds) Dwelling Place and Environment, Lancaster: Martinus Nijhoff.

Brille, Michael (1960) Revolutionary Scenario for an Architects' Education. PA June
Broady, M (1968) Planning for People: Essays on Social Context of Planning. London: Bedford Square Press.

Canter, D V (1977) Psychology of Place, London: Architectural Press.

Coomaraswamy, A K (1981) Sources of Wisdom. Ministry of Cultural Affairs, Sri Lanka.

Dayaratne, R (1992) Supporting People's Place Making: Theory and Practice, an unpublished PhD Thesis submitted to the University of Newcastle upon Tyne, U.K.

Jung, Karl (1938) Psychology and Religion. London: Yale University Press.

Honikman, B (1976) Construct Theory as an Approach to Architectural and Environmental Design, in Slater, $P$ (1976) Eds. Explorations of Interpersonal Space, John Wiley and London Sons.

Kelly G (1955) The Psychology of Personal Constructs, New York: W W Norton.

Lerup, L (1977) Building the Unfinished, Architecture and Human Action. Vol. 53, Saga Library of Social Research, London: Sage Publications.

Pirsig, R (1974) Zen and the Art of Motorcycle Maintenance. London: Vintage.

Rapoport, A (1981) Meaning of the Builtenvironment: A Non-Verabal Communication Approach, London: Sage Publications.

Slater, P (1969) The Theory and Technique of the Repertory Grid, British Joumal of Psychology $115,528$.

Schultz, N (1971) Existence Space and Architecture. New York: Praeger.

Scgultz, N (1980) Genius Loci, Towards a Phenomenology of Architecture. London: Academy Editions.

Sri Nammuni, V (1991a) Teaching of Architectural Design: A Moratuwa Experiment part 1 in SLArchitect, 100(7): 21.

Sri Nammunl, V (1991b) Christoper Alexander and Design Methodology in Architecture. Teaching of Architectural Design: A Moratuwa Experiment part I, SLArchitect, 100(8): 21.

Sri Nammunl, V (1991c) From Learning to Teaching Architecture, Teaching of Architectural Design: A Moratuwa Experiment part 1 in SLArchitect, 100(9): 23.

Srl Nammuni, V (1991d) Design Teaching at Moratuwa, Teaching of Architectural Design: A Moratuwa Experiment, Part 1, SLArchitect, 100(10): 15.

Sri Nammuni, V (1992) Moratuwa Experiment as a Response to Teaching Architecture Design: A Moratuwa Experiment, SLArchitect, 100(11): 47.

Wilk, R., (1990). “The built environment and consumer decisions," in, Kent, S., (ed.), Domestic Architecture \& the User of Space, Cambridge: Cambridge University Press. 